\title{
Journal of Liaquat University of Medical \& Health Sciences (JLUMHS): Bibliometric Profile 2002 - 2015
}

\author{
Zameer Hussain Baladi
}

EDITOR STATEMENT: The views and statistics expressed in this article are of authors and not necessarily reflect views of the editorial staff of JLUMHS.

\section{ABSTRACT}

INTRODUCTION: The aim was to measure and analyze the growth of academic literature, authors' productivity, the affiliation of authors with Institute and geographic locations published in Journal of Liaquat University of Medical \& Health Sciences (JLUMHS) related to any discipline of knowledge through bibliometric study which is used as a tool by library information sciences professionals.

METHODOLOGY: The statistical analysis in MS Excel 2010 was done during mid-April 2016 to mid-November, 2016. The data for study was collected \& downloaded from websites of Journal of Liaquat University of Medical \& Health Sciences, Jamshoro Pakistan (http://www.lumhs.edu.pk/jlumhs) and PakMediNet (http://www.pakmedinet.com/).

RESULTS: During 2002 - 2015, JLUMHS published 14 volumes and 38 issues with 406 articles. The maximum and minimum articles published were 56 and 6 during the years 2009 and 2002, respectively. Majority of articles were written by more than one author $(n=380,93.59 \%)$ followed by $26(6.40 \%)$ by the single author. The highest single institution was Liaquat University of Medical \& Health Sciences Jamshoro / Hyderabad Pakistan to publish 208 (51.23\%) articles through 14 volumes. A gender-wise comparison among the contributing authors revealed male numbered $(n=1142 ; 74.16 \%)$ higher than the female ( $n=398 ; 25.84 \%$ ) out of a total of 406 articles published during 2002-2015.

CONCLUSION: This study reveals that JLUMHS has been nationally circulated and all most all publications have been contributed from the host country. The research productivity publish in this journal disclose that the research in the field of healthcare focuses on resources, services and their effect on quality activities for improving the status of medical care.

KEYWORDS: Bibliometrics, Medical Research, Biomedical Research, Open Access, Publication Analysis

This article may be cited as: Baladi ZH. Journal of Liaquat University of Medical \& Health Sciences (JLUMHS): Bibliometric Profile 2002 - 2015. J Liaquat Uni Med Health Sci. 2017;16(03): 164-70. doi: 10.22442/jlumhs. 171630527

\section{INTRODUCTION}

A bibliometrics study is the branch of library information sciences; it reflects the contribution of authors in the specific area of a subject, specialty and the incline or decline of interest in research. The purpose of this study is to know the statistical information of published material in terms of original articles, review articles and case studies.

Research publications are the embodiments of the intellectual thought contents expressed in published literature whose key objective is to transmit innovative ideas or information to any specific field of knowledge towards the further development of a subject ${ }^{1}$.

Journals to be important channels for dissemination of research outputs, besides, being indispensable for academics and practitioners, such as; author productivity, extent of authors collaboration, authors institutional affiliation, authors geographic affiliation, type of publication, language of papers, number of citations used per article, length of papers, and year-wise distribution of papers ${ }^{2}$.

Kotti Tharamani examined the bibliometric analysis of the Directory of Open Access Journal on the subject of Library and Information Science (LIS). There were 9,804 journals up to Jun 2014, out of this, 151 titles belonged to LIS. Thirty four titles had been identified as interdisciplinary nature of library related journals. There were 40 countries represented in publishing these journals, highest number $(n=37,24.50 \%)$ of journals were produced from USA, published in 24 languages, English language being the highest. Most of the journals were originated by the LIS department of the universities $(43.04 \%)$ followed by other organizations $(37.74 \%)^{3}$.

A cross-sectional study was conducted on the 572 
abstract published in Brazilian Journal of Pediatric Dentistry published during 1998 to 2007 . Most of the researchers $(32.9 \%)$ used "Case Report" as study design followed by Cross-sectional study (29.7\%). Cardiology was the most interesting topic, 120 $(15.3 \%)$ article written on this subject. Author productivity was also present in this paper ${ }^{4}$.

Researchers examined the authorship pattern through the bibliometric analysis of The Indian Journal of Medical Research for the period of 2000 to 2005. Authorship pattern showed that most of the articles $(24.16 \%)$ were produced by three authors, followed by multiple authors $(20.20 \%)$, only $3.33 \%$ articles were written by a single author. The research productivity ratio was higher in Education Institution as compare to Research Organization ${ }^{5}$.

A piloted study was conducted on Iranian research output in pediatric published during 1975-2007 based upon PubMed results. Total 819 articles retrieved from this period with the impact factors were up to 25.8 , and $13.7 \%$ articles had produced with international co-authors. Most of the studies (66.3\%) conducted on children and adolescents with the age of 2-12 years followed by neonates (24.1\%) and infants $(23.6 \%)$. The most common area of research was infectious diseases $(18.7 \%)$. The result revealed that there had been rapid increase in the research of Pediatric science after 2002 in Iran $^{6}$.

A bibliometric study had been conducted on 234 articles published in the 40 issues of Library herald for the period of 10 years, (2003-2012) with an average of 23 articles per year. The gender wise analysis showed that out of 387 authors, $77.2 \%$ were male and $22.8 \%$ were female. Authorship pattern showed that $114(48.8 \%)$ articles were written by single author. Among eight most productive authors, six belonged to the teaching faculty of the universities. Academic Libraries and Information Communication Technology (ICT) were the favorite area of research ${ }^{7}$.

Liaquat University of Medical Health Sciences is the first public sector Medical University has a long history of imparting medical education. It started as a medical school in the present Civil Hospital, Hyderabad in 1881and named Liaquat Medical College in 1951. The first foundation stone of Jamshoro campus laid down in 1954, up-gradation of Medical College to a Medical University on 21st January 2001 to award degree programs with the support of 05 faculties, 49 departments, above 1300 bedded tertiary hospital, state of art laboratories and visionary management in the fields of biomedical, medical and nursing. Journal of Liaquat University of Medical and Health Sciences (JLUMHS) Jamshoro, Pakistan, publishes original manuscripts, case reports and reviews on topics related to medical and health sciences. JLUMHS is a peer - reviewed journal and is published as three issues per year. It updated October 2001 (Refer JLUMHS July - December 2002 issue) $)^{8}$.

\section{Objectives}

The follow objectives of this study were set to get answers:

1. To assess the year, volume \& issue wise publications;

2. To explore the contribution of authors in publications;

3. To know the pattern of authorship;

4. To evaluate the gender wise distribution of the authors;

5. To discover the most contributing institutions/ organizations.

\section{METHODOLOGY}

The data of original articles, review articles and case reports published in JLUMHS during the year 2002 to 2015, was collected \& downloaded for statistical analysis in MS Office (Excel 2010) in the library of College of Applied Medical Sciences, King Saud bin Abdulaziz University for Health Sciences Riyadh, Kingdome of Saudi Arabia throughout the period of mid-August 2016 to mid-November 2016 from websites of the respective e-journal of Liaquat University of Medical \& Health Sciences (http:// www.lumhs.edu.pk/julmhs.), and from Pak Medi Net (http://www.pakmedinet.com/) a participatory research work for helping in respects of references and biostatistics.

\section{RESULTS}

The result in the figure I shows that JLUMHS published a total of 406 papers in all issues during the years 2002-2015. Max. 22 and min. 6 articles published in the JLUMHS during these years.

Table I shows the further break down of the published material.

Figure II: Showed the contribution of authors for 406 articles published in JLUMHS during 2015-2002. The total number of authors who contributed research were 1540 authors .The mean author per article was 3.79 .

Table II shows further break down of research productivity, maximum 142 contributions of authors for 32 artcles in all issues and 39 authors contributed for 16 was the lowest with an average of 2.43 for volume 3 , during year 2004

Figure III revealed that $1142 ; 74.16$ of the authors were male and $398 ; 25.84$ were female for the 
num $=406$ articles.

Table III shows further break down of contributed authors, 165; 10.71 from 230 authors in the year of 2009 volume $8(1-3)$ were male dominant and during the year 2009 volume 8 (1-3) the 65; 4.22 from 230 articles were the highest figure for female.

Figure IV highlighted the contribution of authors in research productivity.

Table IV is designed for knowing the authorship patterns year by year in the different issues of JLUMHS, (1) 118 (29.06) articles from 406 were written by three authors, (2) 109 (26.85) written by four authors, (3) 55 (13.55) articles written by six authors, (4) 47 (11.58) articles written by five authors, (5) 40 (9.85) articles written by two authors and (6) 9 (2.22) articles written by seven authors, (7) 2 (0.49) articles written by eight authors and in least 26 (6.40) articles were solos authors. 303 (74.63) were male authors as first authors and 102 (25.12) were female as first authors.

Table \& Figure V: Distributions of contribution of institutes and organization in JLUMHS.

The 406 articles published by 1540 during 2015-2002 were shared by around 57 worldwide institutes/ organizations. Table 5 shows that the participation by twenty organizations as the major contributors 365 (89.90\%). The Departments / Institutes related to Liaquat University of Medical \& Health Sciences Jamshoro / Hyderabad contributed 208 (51.23\%). Isra University Hyderabad / Karachi \& Islamabad 33 (8.13\%), Civil Hospital Dow University of Health Sciences Karachi 30 (7.39\%), Jinnah Postgraduate Medical Centre (JPMC) 18 (7.43\%), The Agha Khan University Hospital Karachi 13 (3.20\%), Chandka Medical College / Shaheed Mohtarma Benazir Bhutto University for Medical Health Sciences (SMBBUMS) $10(2.46 \%)$.

FIGURE I: DISTRIBUTION OF ARTICLES YEAR, VOLUME \& ISSUE-WISE 2015 - 2002

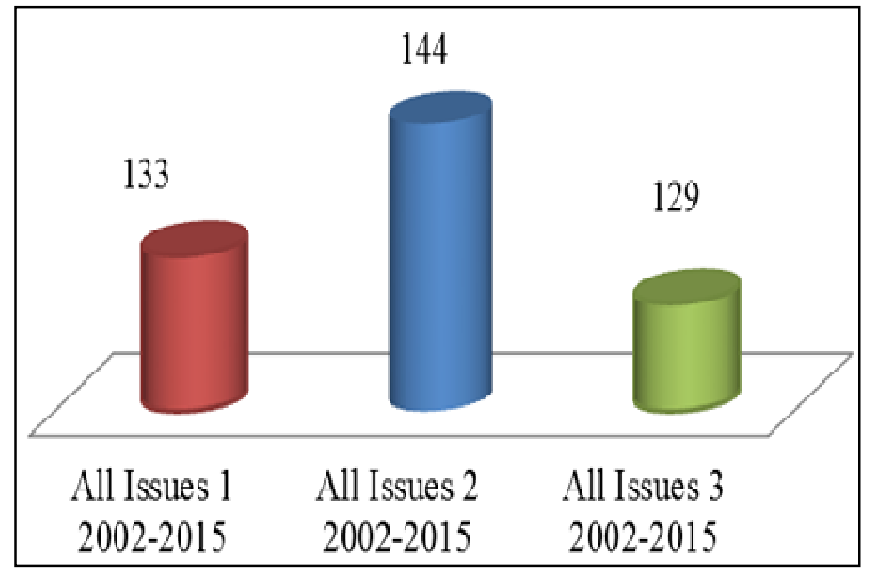

FIGURE II: AUTHORS CONTRIBUTION IN PUBLICATION WITH YEAR, VOLUME \& ISSUE WISE 2002-2015

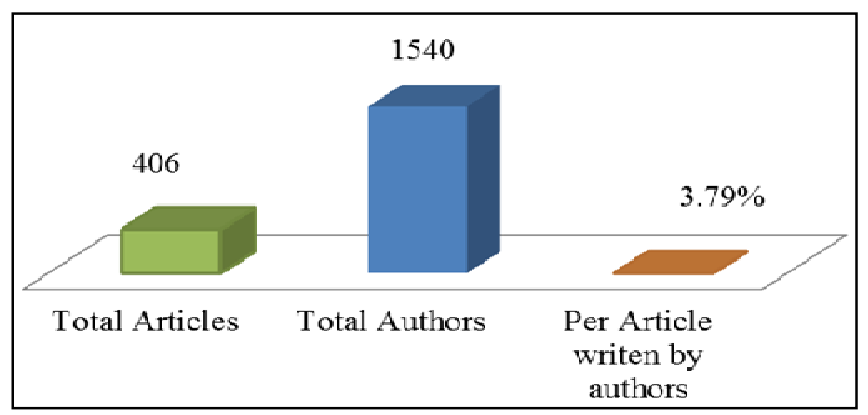

FIGURE III: DISTRIBUTION OF AUTHOR'S CONTRIBUTION AS PER GENDER SPECIFICATION DURING THE YEAR 2002 - 2015

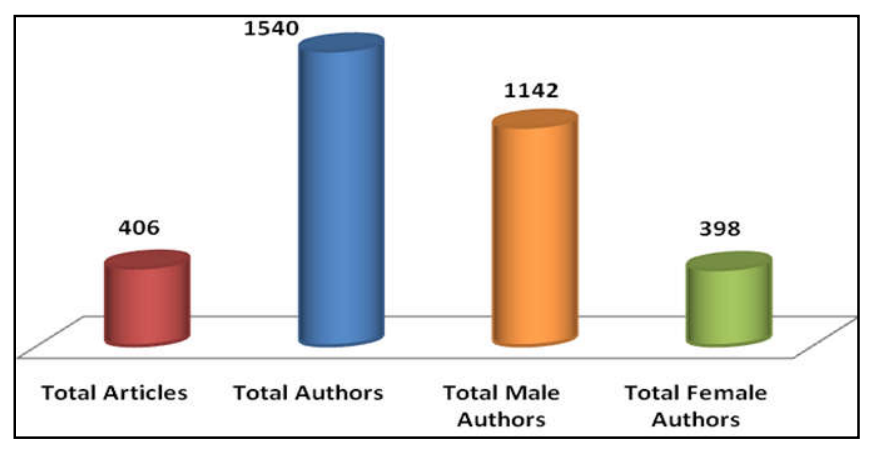

FIGURE IV: AUTHOR SHIP PATTERN YEAR WISE IN JLUMHS 2015-2002

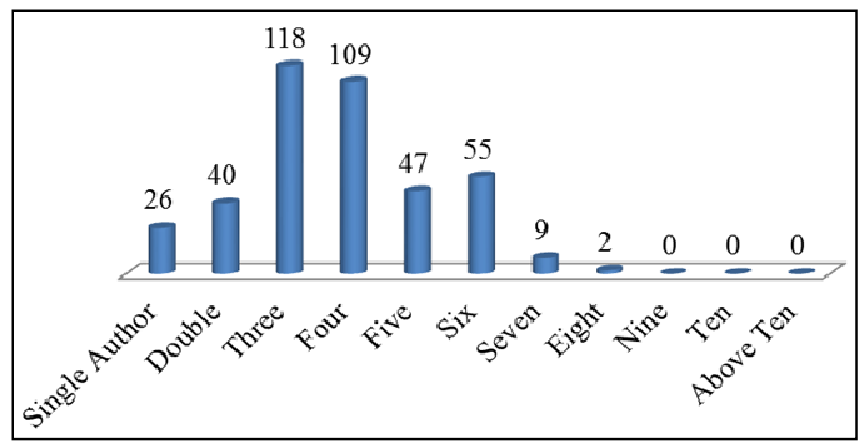

FIGURE V: DISTRIBUTIONS OF CONTRIBUTION OF INSTITUTES AND ORGANIZATIONS IN JLUMHS 2002 - 2015

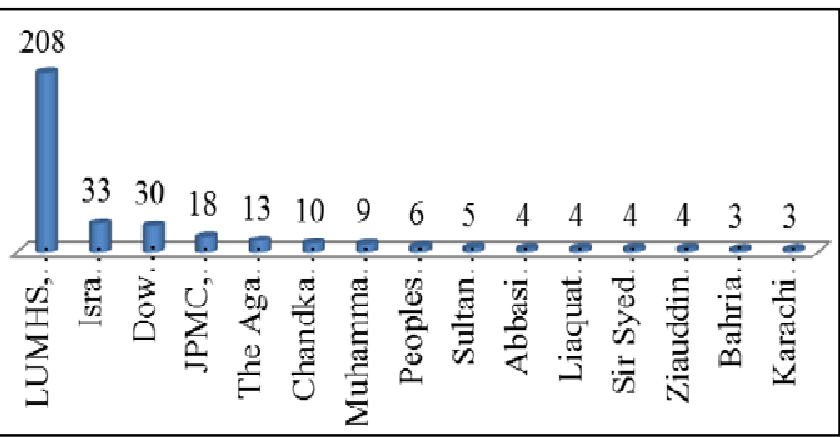


Bibliometric Profile

TABLE I: DISTRIBUTION OF ARTICLES YEAR, VOLUME \& ISSUE-WISE 2015 - 2002

\begin{tabular}{|c|c|c|c|c|c|}
\hline Year & Vol: & $\begin{array}{l}\text { Articles published in all } \\
\text { issues } 1,2002-2015\end{array}$ & $\begin{array}{l}\text { Articles published in all } \\
\text { Issues 2, 2002-2015 }\end{array}$ & $\begin{array}{l}\text { Articles published in all } \\
\text { Issues } 3,2002-2015\end{array}$ & $\begin{array}{l}\text { Total Articles } \\
\text { with \% }\end{array}$ \\
\hline 2015 & 14 & 10 & 8 & 8 & $26(6.40 \%)$ \\
\hline 2014 & 13 & 9 & 8 & 11 & $28(6.90 \%)$ \\
\hline 2013 & 12 & 13 & 15 & 16 & $44(10.84 \%)$ \\
\hline 2012 & 11 & 10 & 13 & 15 & $38(9.36 \%)$ \\
\hline 2011 & 10 & 8 & 9 & 15 & $32(7.88 \%)$ \\
\hline 2010 & 9 & 9 & 10 & 12 & $31(7.64 \%)$ \\
\hline 2009 & 8 & 21 & 22 & 13 & $56(13.79 \%)$ \\
\hline 2008 & 7 & 9 & 18 & 14 & $41(10.10 \%)$ \\
\hline 2007 & 6 & 9 & 8 & 9 & $26(6.40 \%)$ \\
\hline 2006 & 5 & 8 & 9 & 8 & $25(6.16 \%)$ \\
\hline 2005 & 4 & 6 & 9 & 8 & $23(5.67 \%)$ \\
\hline 2004 & 3 & 8 & 8 & NP & $16(3.94 \%)$ \\
\hline 2003 & 2 & 7 & 7 & NP & $14(3.45 \%)$ \\
\hline 2002 & 1 & 6 & NP & NP & $6(1.48 \%)$ \\
\hline \multicolumn{2}{|c|}{ Publication per issue \& $\%$} & $133(32.76 \%)$ & $144(35.47 \%)$ & $129(31.77 \%)$ & 406 \\
\hline \multicolumn{2}{|c|}{ Total Issues 38} & \multicolumn{4}{|c|}{ Articles published in per issue $3.79 \%$} \\
\hline
\end{tabular}

TABLE II: AUTHORS CONTRIBUTION IN PUBLICATION WITH YEAR, VOLUME \& ISSUE-WISE 2002 - 2015

\begin{tabular}{|c|c|c|c|c|}
\hline Years & Volumes & Total Authors & Total Publication & $\begin{array}{c}\text { Distribution of } \\
\text { authors per paper \% }\end{array}$ \\
\hline 2015 & 14 & 104 & 26 & 4 \\
\hline 2014 & 13 & 110 & 28 & 3.92 \\
\hline 2013 & 12 & 173 & 44 & 3.93 \\
\hline 2012 & 11 & 150 & 38 & 4.43 \\
\hline 2011 & 10 & 142 & 32 & 3.90 \\
\hline 2010 & 9 & 121 & 31 & 4.10 \\
\hline 2009 & 8 & 230 & 56 & 4.29 \\
\hline 2008 & 7 & 176 & 41 & 2.92 \\
\hline 2007 & 6 & 76 & 26 & 3.28 \\
\hline 2006 & 5 & 82 & 25 & 3.17 \\
\hline 2005 & 4 & 73 & 23 & 2.43 \\
\hline 2004 & 3 & 39 & 16 & 3.35 \\
\hline 2003 & 2 & 47 & 14 & 2.83 \\
\hline 2002 & 1 & 17 & 6 & 3.79 \\
\hline & Total & 1540 & 406 & \\
\hline
\end{tabular}


Zameer Hussain Baladi

TABLE III: DISTRIBUTION OF AUTHOR'S CONTRIBUTION AS PER GENDER SPECIFICATION WITH YEAR, VOLUME \& ISSUE-WISE

\begin{tabular}{|c|c|c|c|c|}
\hline Year, Volume \& Issue & Articles & Total Authors \% & Total Male Authors \% & Total Female Authors \% \\
\hline 2015 (14) 1 - 3 & 26 & $104(6.75 \%)$ & $70(4.55 \%)$ & $34(2.21 \%)$ \\
\hline 2014 (13) 1 - 3 & 28 & $110(7.14 \%)$ & $85(5.52 \%)$ & $25(1.62 \%)$ \\
\hline $2013(12) 1-3$ & 44 & $173(11.23 \%)$ & $131(8.51 \%)$ & $42(2.73 \%)$ \\
\hline $2012(11) 1-3$ & 38 & $150(9.74 \%)$ & $106(6.88 \%)$ & $44(2.86 \%)$ \\
\hline 2011 (10) 1 - 3 & 32 & $142(9.22 \%)$ & $109(7.08 \%)$ & $33(2.14 \%)$ \\
\hline 2010 (9) 1 - 3 & 31 & $121(7.86 \%)$ & $94(6.10 \%)$ & $27(1.75 \%)$ \\
\hline 2009 (8) 1 - 3 & 56 & $230(14.94 \%)$ & $165(10.71 \%)$ & $65(4.22 \%)$ \\
\hline $2008(7) 1-3$ & 41 & $176(11.43 \%)$ & $138(8.96 \%)$ & $38(2.47 \%)$ \\
\hline 2007 (6) 1 - 3 & 26 & $76(4.94 \%)$ & $54(3.51 \%)$ & $22(1.43 \%)$ \\
\hline $2006(5) 1-3$ & 25 & $82(5.32 \%)$ & $58(3.77 \%)$ & $24(1.56 \%)$ \\
\hline 2005 (4) $1-3$ & 23 & $73(4.74 \%)$ & $49(3.18 \%)$ & $24(1.56 \%)$ \\
\hline $2004(3) 1-2$ & 16 & $39(2.53 \%)$ & $30(1.95 \%)$ & $9(0.58 \%)$ \\
\hline $2003(2) 1-2$ & 14 & $47(3.05 \%)$ & $39(2.53 \%)$ & $8(0.52 \%)$ \\
\hline 2002 (11) 1 & 6 & $17(1.10 \%)$ & $14(0.91 \%)$ & $3(0.19 \%)$ \\
\hline Total Papers & 406 & 1540 & $1142(74.16 \%)$ & $398(25.84 \%)$ \\
\hline
\end{tabular}

TABLE IV: AUTHOR SHIP PATTERN YEAR WISE IN JOURNAL OF LIAQUAT UNIVERSITY OF MEDICAL \& HEALTH

\begin{tabular}{|c|c|c|c|c|c|c|c|c|c|c|c|c|c|c|c|}
\hline $\begin{array}{l}\text { Author- } \\
\text { ship } \\
\text { Pattern }\end{array}$ & $\begin{array}{l}2015 \\
(14) \\
1-3\end{array}$ & $\begin{array}{c}2014 \\
(13) \\
1-3\end{array}$ & $\begin{array}{c}2013 \\
(12) \\
1-3\end{array}$ & $\begin{array}{l}2012 \\
(11) \\
1-3\end{array}$ & $\begin{array}{l}2011 \\
(10) \\
1-3\end{array}$ & $\begin{array}{c}2010 \\
(9) \\
1-3\end{array}$ & $\begin{array}{c}2009 \\
(8) \\
1-3\end{array}$ & $\begin{array}{c}2008 \\
(7) \\
1-3\end{array}$ & $\begin{array}{c}2007 \\
(6) \\
1-3\end{array}$ & $\begin{array}{c}2006 \\
(5) \\
1-3\end{array}$ & $\begin{array}{c}2005 \\
(4) \\
1-3\end{array}$ & $\begin{array}{c}2004 \\
(3) \\
1-2\end{array}$ & $\begin{array}{c}2003 \\
(2) \\
1-2\end{array}$ & $\begin{array}{c}2002 \\
(1) \\
1\end{array}$ & $\begin{array}{c}\text { No of } \\
\text { Authors } \\
\& \%\end{array}$ \\
\hline Single & 1 & 2 & 0 & 1 & 1 & 0 & 0 & 3 & 6 & 2 & 4 & 4 & 2 & 0 & $26(6.40 \%)$ \\
\hline Double & 1 & 0 & 3 & 0 & 1 & 5 & 5 & 2 & 6 & 5 & 3 & 5 & 3 & 1 & $40(9.85 \%)$ \\
\hline Three & 9 & 7 & 12 & 12 & 10 & 8 & 15 & 11 & 7 & 8 & 7 & 5 & 2 & 5 & $118(29.06 \%)$ \\
\hline Four & 7 & 13 & 19 & 16 & 5 & 8 & 19 & 7 & 2 & 5 & 5 & 0 & 3 & 0 & $109(26.85 \%)$ \\
\hline Five & 4 & 1 & 5 & 5 & 3 & 5 & 6 & 5 & 2 & 4 & 2 & 2 & 3 & 0 & 47 (11.58\%) \\
\hline Six & 2 & 5 & 5 & 4 & 10 & 5 & 9 & 9 & 2 & 1 & 2 & 0 & 1 & 0 & $55(13.55 \%)$ \\
\hline Seven & 2 & 0 & 0 & 0 & 2 & 1 & 3 & 1 & 0 & 0 & 0 & 0 & 0 & 0 & $9(2.22 \%)$ \\
\hline Eight & 0 & 0 & 0 & 0 & 0 & 0 & 0 & 1 & 1 & 0 & 0 & 0 & 0 & 0 & $2(0.49 \%)$ \\
\hline Nine & 0 & 0 & 0 & 0 & 0 & 0 & 0 & 0 & 0 & 0 & 0 & 0 & 0 & 0 & 0 \\
\hline Ten & 0 & 0 & 0 & 0 & 0 & 0 & 0 & 0 & 0 & 0 & 0 & 0 & 0 & 0 & 0 \\
\hline Above Ten & 0 & 0 & 0 & 0 & 0 & 0 & 0 & 0 & 0 & 0 & 0 & 0 & 0 & 0 & 0 \\
\hline $\begin{array}{l}\text { Contribution of } \\
\text { multi authors }\end{array}$ & $\begin{array}{c}26 \\
6.40 \%\end{array}$ & $\begin{array}{c}28 \\
6.90 \%\end{array}$ & $\begin{array}{c}44 \\
10.84 \%\end{array}$ & $\begin{array}{c}38 \\
9.36 \%\end{array}$ & $\begin{array}{c}32 \\
7.88 \%\end{array}$ & $\begin{array}{c}32 \\
7.88 \%\end{array}$ & $\begin{array}{c}57 \\
14.04 \%\end{array}$ & $\begin{array}{c}39 \\
9.61 \%\end{array}$ & $\begin{array}{c}26 \\
6.40 \%\end{array}$ & $\begin{array}{c}25 \\
6.16 \%\end{array}$ & $\begin{array}{c}23 \\
5.67 \%\end{array}$ & $\begin{array}{c}16 \\
3.94 \%\end{array}$ & $\begin{array}{c}14 \\
3.45 \%\end{array}$ & $\begin{array}{c}6 \\
1.48 \%\end{array}$ & 406 \\
\hline
\end{tabular}


Bibliometric Profile

TABLE V: DISTRIBUTIONS OF CONTRIBUTION OF INSTITUTES AND ORGANIZATIONS IN JLUMHS 2015 - 2002

\begin{tabular}{|c|l|r|}
\hline \multicolumn{2}{|c|}{ Contribution of Institutes and Organizations in JLUMHS 2002 - 2015 } & Published Articles \& \% \\
\hline 1 & LUMHS, Jamshoro/ Hyderabad & $208(51.23 \%)$ \\
\hline 2 & Isra University, Hyderabad, Sindh- Pakistan & $33(8.13 \%)$ \\
\hline 3 & Dow University of Health Sciences/Civil Hospital Karachi & $30(7.39 \%)$ \\
\hline 4 & JPMC, Karachi & $18(4.43 \%)$ \\
\hline 5 & The Aga Khan University, Stadium Road, Karachi & $13(3.20 \%)$ \\
\hline 6 & Chandka Medical College Teaching Hospital, Larkana & $10(2.46 \%)$ \\
\hline 7 & Muhammad Medical College, Mirpurkhas & $9(2.22 \%)$ \\
\hline 8 & Peoples University of Medical \& Health Sciences, Nawabshah & $6(1.48 \%)$ \\
\hline 9 & Sultan Qaboos University Hospital Muscat. Sultanate of Oman & $5(1.23 \%)$ \\
\hline 10 & Abbasi Shaheed Hospital, Karachi & $4(0.99 \%)$ \\
\hline 11 & Liaquat National Hospital, Karachi & $4(0.99 \%)$ \\
\hline 12 & Sir Syed College of Medical Sciences Karachi & $4(0.99 \%)$ \\
\hline 13 & Ziauddin Medical University, Karachi & $4(0.99 \%)$ \\
\hline 14 & Bahria University Medical \& Dental College Karachi & $3(0.74 \%)$ \\
\hline 15 & Karachi Medical \& Dental College, Karachi & $3(0.74 \%)$ \\
\hline & Total Articles by institutes and organizations 406 - 354 = 52 & $354(87.19 \%)$ \\
\hline & Remaining Articles related to various individual's, Institutes and Organizations & $52(12.80 \%)$ \\
\hline
\end{tabular}

\section{DISCUSSION \& CONCLUSION}

The contribution of articles to each volume of Journal of Liaquat University of Medical \& Health Sciences Jamshoro, Pakistan is constantly stable. The average number of papers per volume is 29 , and $10.68 \%$ per issue. It is revealed that Max number of articles is 22 $(5.41 \%)$ and $\min$ is $6(1.47 \%)$. The contribution of authors for each issue is 1540 (2.46\%) for 406 articles shows that collaborative research is strengthening. Most of the articles 380; 93.59\%) were written by multi authors and $26(6.40 \%)$ articles written by a single author. The participation of Liaquat University of Medical \& Health Sciences Jamshoro / Hyderabad Pakistan in a publication is high. It reveals in this study that participation of female researcher $398 ; 25.84 \%$ from 406 articles of in JLUMHS 2015 - 2000 is quite good. This quantitative study show numbers to gauge and to inform researchers of the field about the research productivity.

Disclaimer: this retrospective study is to provide only numbers not inclined or declined growth of any organization and their standards.

\section{REFERENCES}

1. Warriach NF, Ahmad S. Pakistan Journal of Library and Information Science: A bibliometric analysis. PJIM \&I_2016; 12:1-7.

2. Smita SP, Vaishali SK. Research productivty of faculties in SRTMUN Sub-centre, Latur: A bibliometric study. E-Library Science Research J. 2016; 4(7):1-11.

3. Thavamani K. Directory of Open Access Journals: A bibliometric study of library and information science. Collaborative Librarianship. 2013; 5(4):5.

4. Poletto VC, Faraco Junior IM. Bibliometric study of articles published in a Brazilian Journal of Pediatric Dentistry. Braz Oral Res. 2010;24(1):83-8.

5. Manivannan G. The Indian Journal of Medical Research 2002 - 2005: A bibliometric analysis. J Adv Lib Inf Sci. 2012; 2:100-03.

6. Malekahmadi MR, Moazen B, Khoshdel A, Rahimzadeh F, Lankarani MM. Iranian research output in pediatrics: 1975-2007. J Res Med Sci. 2011; 16(12):1605-1611. 
7. Singh KP, Bebi. Library Herald: A Bibliometric Study (2003-2012). Library Herald. 2014;52(1):19 $-27$.

8. Liaquat University of Medical \& Health Sciences. A brief introduction of JLUMHS [Internet] Journal of Liaquat University of Medical \& Health Sciences 2016 [cited 15 October 2016]. Available from http://www.lumhs.edu.pk/jlumhs/ instructions.php.

\section{䉼}

AUTHOR AFFILIATION:

Zameer Hussain Baladi

Lecturer - Cum - Librarian

King Saud Bin Abdul_aziz University for Health Sciences, College of Applied Medical Sciences,

Riyadh. Kingdom of Saudi Arabia.

Email: zameer.baladi@gmail.com baladiz@ksau-hs.edu.sa 